\title{
PERCURSO POLÍTICO E HISTÓRICO DO PROGRAMA DINHEIRO DIRETO NA ESCOLA E A PARCERIA PÚBLICO-PRIVADA NA GESTÃO ESCOLAR
}

\author{
Edwylson de Lima Marinheiro ${ }^{1}$ \\ Maria José Ferreira Ruiz ${ }^{2}$
}

\section{RESUMO}

O Programa Dinheiro Direto na Escola (PDDE), elaborado na década de 1990, é um programa que utiliza o mecanismo de transferência de recursos financeiros da União para escolas públicas. Tal programa, busca ampliar a autonomia da gestão da escola para administrar diretamente os recursos destinados à manutenção de sua infraestrutura física e pedagógica. Diante disso, o objetivo deste texto é explicitar os princípios e fundamentos históricos, políticos e econômicos do PDDE e suas implicações para a gestão escolar. A questão norteadora do texto gira em torno de buscar responder se o PDDE tem contribuído para democratizar a gestão da escola pública. Como procedimentos de estudo utilizamos a pesquisa bibliográfica e a pesquisa documental. A pesquisa é embasado em vários autores que se debruçam sobre o tema em tela, a exemplo de Adrião e Peroni (2007a), Shiroma; Moraes; Evangelista (2000), Vieira (2013), Branco (2006), Santana (2011) e outros. Conclui que o PDDE, mesmo sendo um recurso público, favorece o fortalecimento das parcerias público-privadas.

Palavras-chave: Política educacional; Programa Dinheiro Direto na Escola; Gestão Escolar; Parceria público-privada.

\section{THE POLITICAL AND HISTORICAL PATH OF THE DIRECT MONEY PROGRAM AT SCHOOL AND THE PUBLIC-PRIVATE PARTNERSHIP IN SCHOOL MANAGEMENT}

\begin{abstract}
The Direct Money in School Program, developed in the 1990s, is a program that uses the transfer mechanism of funding for public schools. This program seeks to expand the school management autonomy to directly manage the resources for the maintenance of their physical and educational infrastructure. Thus, the purpose of this article is to explain the principles and historical background, political and economic of the Direct Money in School Program and its implications for school management. As study procedures used the bibliographical research and document research. The research is grounded in several authors that focus on the subject in the screen, like Adrião and Peroni (2007a), Shiroma; Moraes; Evangelista (2000), Vieira (2013 ), White ( 2006) Santana (2011 ) and others.It concludes that the PDDE, even being a public resource, favors the strengthening of publicprivate partnerships.
\end{abstract}

Keywords: Educational policy; Direct Money in School Program; School management; Public-private partnerships. 


\section{Introdução}

O texto é parte readaptada de estudo de maior amplitude, desenvolvido em Programa de Pós-Graduação strictou sensu, intitulado, "O Programa Dinheiro Direto na Escola e a democratização da Gestão Escolar no município de Londrina-PR. A pesquisa em questão analisa o Programa Dinheiro Direto na Escola (PDDE) e as suas implicações para a democratização da gestão escolar. $\mathrm{O}$ estudo está vinculado ao Grupo de Pesquisa Estado, Políticas Públicas e Gestão da Educação. O interesse pelo estudo sobre a gestão escolar e sobre as fontes de recursos financeiros da escola pública brasileira, tem ocupado a agenda das pesquisas na área da educação, principalmente, após a redefinição do papel do estado e as reformas educacionais, empreendidas após os anos 1990.

O Programa Dinheiro Direto na Escola (PDDE), elaborado neste processo de redefinição das ações estatais, enfatiza a reestruturação institucional das unidades escolares e dos órgãos públicos e foi instituído em 1995, pelo governo federal. O PDDE foi o primeiro a utilizar o mecanismo de transferência de recursos financeiros da União para escolas públicas. Em tese, o que o programa trouxe de novo foi a ampliação da autonomia da escola para administrar diretamente os recursos destinados à manutenção de sua infraestrutura física e pedagógica. Diante deste contexto, o estudo analisa o processo de implementação do Programa Dinheiro Direto na Escola (PDDE), nas escolas da rede municipal de Londrina - PR, visto que, mesmo sendo de caráter suplementar, este programa promove inúmeras indefinições quanto sua finalidade de descentralização de recursos.

O interesse específico em estudar o PDDE foi motivado pela possibilidade de investigar os novos padrões de gestão educacional, que começaram a ser postos em prática, principalmente, no governo do presidente Fernando Henrique Cardoso (FHC), vigente no período de 1995 a 2002, na perspectiva de colaborar com elementos de avaliação do suposto processo de descentralização dos recursos da educação para as unidades escolares.

$\mathrm{O}$ artigo que ora se apresenta, problematiza sobre as possibilidades e limites do PDDE contribuir, ou não, para democratizar a gestão da escola pública. A concepção de democratização do texto, diz respeito à ampliação das formas de participação política da comunidade nas decisões dos assuntos que emergem no contexto da escola pública. Entendemos a democratização, a partir dos estudos críticos sobre a democracia liberal capitalista de Wood (2006).

Tem como objetivo explicitar os princípios e fundamentos históricos, políticos e econômicos do PDDE. Para isto, utilizamos da abordagem qualitativa de pesquisa. Como ponto de partida, realizamos pesquisa bibliográfica, em livros, periódicos, enciclopédias, ensaios críticos, dicionários e artigos científicos. A pesquisa bibliográfica é um tipo de "estudo direto em fontes científicas, sem precisar recorrer diretamente aos fatos/fenômenos da realidade empírica" (OLIVEIRA, 2007, p. 69). Neste sentido, a pesquisa bibliográfica proporciona o contato direto com os referenciais bibliográficos de autores e pesquisadores que se dedicam a estudar a política de financiamento da educação brasileira e outros elementos importantes para o entendimento do tema em tela.

Além da pesquisa bibliográfica, usamos também a pesquisa documental como um importante instrumento de análise e avaliação da implementação das políticas educacionais. Os documentos analisados foram o Plano Diretor da Reforma do Aparelho de Estado (PDRAE) e aqueles mais específicos sobre o PDDE (Medida Provisória n. 1784/98; Resolução n. 10/2013). Estas análises foram feitas, uma vez que os documentos constituem uma fonte estável e rica, e no caso da pesquisa em políticas educacionais, eles não expressam somente diretrizes para a educação, mas articulam interesses, projetam 
políticas, produzem intervenções sociais. Para trabalhar com eles devemos considerar que os mesmos são resultados de práticas sociais e de expressão da consciência humana possível em um dado momento histórico (EVANGELISTA, 2009).

Cabe salientar que os programas educacionais são resultados de uma combinação complexa de diversos agentes que são condicionantes para a sua implementação. Arretche (2001, p. 3) destaca a complexidade do estudo de um programa público, destacando que "as vontades, os interesses, as lealdades e as concepções ideológicas dos diversos agentes envolvidos em um programa público dificilmente serão inteiramente coincidentes". Portando, há muitas divergências em todo o contexto de sua implementação, o que pode descaracterizá-lo daquilo que foi pensado inicialmente pelos seus propositores.

$\mathrm{Na}$ sequência, o texto organiza-se em três seções que se articulam entre si. A primeira delas, mais geral, discute o contexto político e econômico no qual as políticas para a educação foram elaboradas, na década de 1990. A seguir apresenta o PDDE, como uma importante política de descentralização de recursos financeiros para a escola. A terceira e última faz um entrelaçamento entre o contexto político e econômica da Reforma do Estado, relacionando-o com a implantação do PDDE, apresentando as contradições que emergem na implementação deste programa, tendo em vista o curso das políticas neoliberais no Brasil. Como é sabido, estas políticas imprimem a lógica do setor privado empresarial, no contexto da escola pública, que por ser pública precisa ser gerida com os recursos públicos e não em regime de parceria público-privada. Mais adiante estas questões serão melhor explicitadas.

\section{Política Educacional na década de 1990 e o PDDE}

A política educacional brasileira, no contexto da década de 1990, foi redefinida, concomitantemente, com a elaboração e implementação do Plano Diretor da Reforma do Aparelho do Estado no Brasil, que resultou em alterações no papel do Estado brasileiro. Deste modo, o Estado afasta-se cada vez mais da sua função de promotor e provedor das condições necessárias para a efetivação das políticas sociais. Exemplo notório são as parcerias público-privadas, por meio das quais parte das políticas públicas passam a ser efetivadas, em um sistema de solidariedade e filantropia.Importante destacar que em nosso estudo, tratamos do Estado como

[...] expressão das formas contraditórias das relações de produção que se instalam na sociedade civil, delas é parte essencial, nelas tem fincada sua origem e são elas, em última instância, que historicamente delimitam e determinam suas ações (SHIROMA; MORAES; EVANGELISTA; 2000, p. 8).

Nosso entendimento é de que as políticas educacionais não são frutos de iniciativas abstratas, mas sim expressões de uma condição histórica, na qual resultam antagonismos de interesses das classes sociais: burguesia e proletariado.

Tendo isso em vista, a partir da década de 1970, o mundo passou a presenciar uma crise do sistema de produção capitalista. Depois de um longo período de prosperidade econômica, de acumulação de capitais, com auge do fordismo e do keynesianismo ${ }^{3}$, o capital passou a dar sinais de um quadro crítico, demonstrados por alguns elementos como a tendência decrescente da taxa de lucro, decorrente do excesso de produção e a crise em relação à organização do trabalho embasada no fordismo. Esta "crise estrutural do capital" impulsionou, principalmente, nos anos 1980, uma gama de transformações políticas, 
econômicas e sociais e, nestas condições, o sistema capitalista vai buscar formas de restabelecer o padrão de acumulação.

De acordo com Anderson (1995), neste momento foram estabelecidas as condições ideais para a implementação das teses neoliberais, principalmente, com as eleições de Margareth Thatcher, em 1979, na Inglaterra, e Ronald Reagan, em 1980, nos Estados Unidos. Neste cenário, realizaram-se reuniões com organismos multilaterais e representantes da economia para diminuir os efeitos da crise econômica, que desencadearamem uma diversidade de políticas influenciadas pelos organismos internacionais. Como sinalizam Frigotto e Ciavatta (2003),

Os protagonistas destas reformas seriam os organismos internacionais e regionais vinculados aos mecanismos de mercado e representantes encarregados, em última instância, de garantir a rentabilidade do sistema capital, das grandes corporações, das empresas transnacionais e das nações poderosas onde aquelas têm suas bases e matrizes. Nesta compreensão, os organismos internacionais, como o Fundo Monetário Internacional (FMI), Banco Mundial (BIRD), o Banco Interamericano de Desenvolvimento (BID) e o Programa das Nações Unidas para o Desenvolvimento (PNUD), passam a ter o papel de tutoriar as reformas dos Estados nacionais, mormente dos países do capitalismo periférico e semiperiférico (Arrighi, 1998). No plano jurídico econômico, a Organização Mundial do Comércio (OMC) vai tecendo uma legislação cujo poder transcende o domínio das megacorporações e empresas transnacionais (FRIGOTTO; CIAVATTA, 2003, p. 96).

Neste contexto, inúmeras publicações destes organismos influenciam as reformas educacionais que se efetivaram no país e passaram a seguir um novo rumo, definido pelo Consenso de Washington (1989). Segundo Fiori (2001), o Consenso diz respeito a um conjunto de princípios e políticas econômicas de cunho neoliberal, defendido pelas principais economias capitalistas e pelas instituições multinacionais sediadas na cidade de Washington. Idealizado durante a década de 1980, na forma de uma série de medidas para a crise econômica da periferia capitalista, constituiu-se em reformas favoráveis ao mercado. Estas séries de recomendações, visando ao desenvolvimento econômico, atingiram diversos campos, inclusive o educacional.

Em 1990, realizou-se em Jomtien (Tailândia) a "Conferência Mundial sobre Educação para Todos", na qual se estabeleceu um grande projeto mundial para a educação. Com a participação de 155 governos que se comprometeram a assegurar uma educação básica de qualidade para todos. Tal Conferência foi organizada pelas agências: Organização das Nações Unidas para a Educação, Ciência e a Cultura (UNESCO), Fundo das Nações Unidas para a Infância(UNICEF), Programa das Nações Unidas para o Desenvolvimento (PNUD) e o Banco Mundial (SHIROMA; MORAES; EVANGELISTA; 2000).

Em 1996, o Relatório Delors foi publicado em documento intitulado "Educação um Tesouro a Descobrir", para o qual a educação deve ser pensada ao longo da vida, voltada para o desenvolvimento de habilidades e competências necessárias na sociedade moderna. Esta missão passa a ser de responsabilidade da comunidade local, das autoridades oficiais e da comunidade internacional (SHIROMA; MORAES; EVANGELISTA; 2000).

Em anos anteriores, em 1990, a Comissão Econômica para a América Latina e o Caribe $^{4}$ (CEPAL) já havia produzido um documento de cunho econômico (Transformacion Productiva con Equidad), no qual alertava para a necessidade de mudanças educacionais 
devido à reestruturação produtiva em curso. Em 1992, outro importante documento, oEducación y conocimiento: eje de la transformación productiva con equidade foi apresentado e

[...] enfatizava a necessidade de reformas administrativas que operassem uma transmutação do Estado administrador e provedor para um Estado avaliador, incentivador e gerador de políticas. Para tanto, recomendava que se conjugassem esforços de descentralização e de integração, o que pode ser traduzido em desconcentração de tarefas e concentração de decisões estratégicas (SHIROMA; MORAES; EVANGELISTA, 2000, p. 64).

Este conjunto de determinações produzidas pelos organismos multilaterais foi influente na Reforma do Estado Brasileiro, na década de 1990 que marcou a redefinição do papel do Estado, por meio de ações de minimização de sua interferência nas áreas sociais, entre as quais, a educação. Esta reforma é pautada na Terceira Via, que tem sido caracterizada como forma de,

[...] "reconciliar a direita e a esquerda, por meio de uma política econômica conservadora e de uma política social progressista"; terceira via como "centrismo radical"; nem máxima interferência do Estado (como no socialismo), nem mínima interferência estatal (como no liberalismo); responsabilidade fiscal dos governantes, combate à miséria, carga tributária proporcional à renda; responsabilidade do Estado na segurança, na saúde, na educação, na previdência (VIEIRA, 2013, p. 196, grifos do autor).

A Terceira Via, iniciada na Inglaterra, tenta ser, supostamente, uma alternativa, colocando-se entre a direita e a esquerda. Por um lado, apresenta-se como uma alternativa ao neoliberalismo ortodoxo ${ }^{5}$, que defende a concepção de livre mercado e do estado mínimo para o social. Por outro, não pretende ser a antiga social democracia, pois não quer o Estado como garantidor das políticas sociais (PERONI, 2013).

Podemos destacar, segundo Peroni (2013), que a principal estratégia da Terceira Via foi a Reforma do Estado, ocorrida em 1995, influenciada pelas novas orientações dos organismos multilaterais e pelas definições econômicas do Consenso de Washington. A Reforma do Aparelho do Estado originou-se como um dos mecanismos de superação da crise do capitalismo mundial, cujo diagnóstico era de que a natureza burocrática e regulatória do Estado fora o elemento causador da crise.

A Reforma do Estado no Brasil foi implementada, de fato, na gestão do presidente Fernando Henrique Cardoso (1995-2002), que inicia seu governo, organizando uma ampla reforma nas políticas e nos aparelhos do Estado, com o objetivo de solucionar a crise da economia brasileira e garantir as condições de inserção do país numa economia globalizada (CARDOSO, 1998). Para isso, foi criado o Ministério da Administração Federal e Reforma do Estado (MARE) ${ }^{6}$, cujo objetivo foi a promoção de uma ampla reforma do aparelho do Estado, no que diz respeito a sua estrutura e funcionamento, tendo como ministro Luiz Carlos Bresser Pereira, que formulou o Plano Diretor da Reforma do Estado (PDRAE).

A justificativa que determinou as mudanças no Estado Nacional brasileiro foi a de que o Estado se encontrava em crise devido à deficiência dos processos econômicos sociais e políticos, causada pelos gastos excessivos do Estado com o social e a ineficiência do estado burocrático (BRASIL, 1995). 
Diante desse diagnóstico, o Plano Diretor de Reforma do Aparelho do Estado propõe mudanças a partir da criação de mecanismos de reestruturação da estrutura organizacional do Estado como a descentralização, desburocratização e a focalização na avaliação de resultados. Na tentativa de superar a suposta crise, o documento ainda destaca que

É preciso, agora, dar um salto adiante, no sentido de uma administração pública que chamaria de "gerencial", baseada em conceitos atuais de administração e eficiência, voltada para o controle dos resultados e descentralizada para poder chegar ao cidadão, que, numa sociedade democrática, é quem dá legitimidade às instituições e que, portanto, se torna "cliente privilegiado" dos serviços prestados pelo Estado (BRASIL 1995, p. 7).

Desse modo, uma das estratégias adotadas pelo Governo Federal para que este pudesse alcançar resultados de qualidade e eficiência em sua administração, seria a descentralização, entendida como a transferência de responsabilidade de gestão e financiamento das atividades públicas para os Estados e Municípios. Previa, também, a valorização das parcerias entre o Estado e as organizações sociais, que, embora sejam organizações de direito privado, prestam serviços considerados públicos. Estas organizações da sociedade civil vão compreender o que se chama público não-estatal ${ }^{7}$.

Segundo o PDRAE (BRASIL, 1995), a reforma do aparelho do Estado era uma meta que traria, para o governo de Fernando Henrique Cardoso, maior possibilidade de governança, assim como eficiência e melhor qualidade dos serviços prestados, denominado, no Plano Diretor de cidadão-cliente.

De acordo Pereira (1998),

A governabilidade e a governança são conceitos mal definidos, frequentemente confundidos. Para mim, governabilidade é uma capacidade política de governar derivada da relação de legitimidade do Estado e do seu governo com a sociedade; governança é a capacidade financeira e administrativa, em sentido amplo, de um governo implementar políticas (PEREIRA, 1998, p. 33).

Assim o Aparelho do Estado é entendido como:

[...] administração pública em sentido amplo, ou seja, a estrutura organizacional do Estado em seus três poderes (Executivo, Legislativo e Judiciário) e três níveis (União, Estados membros e Municípios). O aparelho do Estado é constituído pelo governo, isto é, pela cúpula dirigente nos Três Poderes, por um corpo de funcionários, e pela força militar. O Estado, por sua vez, é mais abrangente que o aparelho, porque compreende adicionalmente o sistema constitucional-legal, que regula a população nos limites de um território. O Estado é a organização burocrática que tem o monopólio da violência legal, é o aparelho que tem o poder de legislar e tributar a população de um determinado território. (BRASIL, 1995a, p. 12).

O aparelho do Estado é toda a organização estrutural que tem por objetivo a prestação de serviços de acordo com o interesse social. Neste contexto, a Reforma do Aparelho do Estado, a partir dos anos 1990, trouxe grandes modificações na relação entre 
Estado e Sociedade Civil. As reformas no campo educacional, na década de 1990, entram como estratégia para o desenvolvimento da economia. Nesta perspectiva, para os reformadores, o problema da educação não seria a falta recursos, mas sim uma ineficiência na sua administração. A educação básica estaria no foco das políticas, pois

[...] A educação, especialmente a primária e a secundária (educação básica), ajuda a reduzir a pobreza aumentando a produtividade do trabalho dos pobres, reduzindo a fecundidade, melhorando a saúde, e dota as pessoas de atitudes de que necessitam para participar plenamente na economia e na sociedade. (SHIROMA; MORAES; EVANGELISTA, 2000, pp. 74-75).

Neste período histórico, a organização das políticas e dos projetos educacionais parte da ideia de que a crise é fiscal e, para isso, propõe políticas para a racionalização dos recursos, sendo a descentralização uma destas estratégias. As consequências para as políticas sociais, em específico para a educação, são muitas. A ideia é diminuir gastos com esta área, em parte, descentralizando tarefas para as escolas e centralizando o poder de decisão nas mãos do Estado. Repassa-se, assim, para a sociedade o compromisso com o financiamento e a coordenação das políticas. Por outro lado, centraliza-se, por meio da fiscalização, controle de avaliação e indicadores de qualidade.

Conforme Adrião e Peroni (2005)

Essas alterações não ocorrem apenas na política educacional. Visto que são observadas nas políticas sociais de uma maneira geral e resultam das estratégias adotadas pelos setores hegemônicos como resposta à crise do capitalismo. [...] destaca-se neste trabalho o processo de configuração do terceiro setor na gestão da escola pública brasileira, por meio do Programa Dinheiro Direto na Escola - PDDE (ADRIÃO; PERONI, 2005, pp. 137-138).

De acordo com as ideias das autoras, o PDDE leva-nos a uma tendência de privatização dos sistemas públicos de ensino, introduzindo a lógica privada na gestão pública, como se pode verificar na sequência do texto. Tendo isto em vista, no próximo item, apresentamos o histórico do Programa Dinheiro Direto na Escola (PDDE) e sua relação com o Plano Diretor de Reforma do Aparelho do Estado (PDRAE).

\section{O Programa Dinheiro Direto na Escola: constituição histórica}

O Programa Dinheiro Direto na Escola foi criado pelo governo federal em 1995 com a denominação de Programa de Manutenção e Desenvolvimento do Ensino Fundamental (PMDE), posteriormente, sendo alterado para Programa Dinheiro Direto na Escola (PDDE), e executado pelo Fundo Nacional de Desenvolvimento Educacional (FNDE), por força de Medida Provisória $\mathrm{n}^{\circ}$ 1784, de 14 de dezembro de 1998. Sua concepção baseou-se no princípio de descentralização da execução dos recursos federais destinados ao Ensino Fundamental e ao reforço ao exercício da cidadania. 
Art. $2^{\circ}$ O Programa Dinheiro Direto na Escola (PDDE) consiste na destinação anual, pelo Fundo Nacional de Desenvolvimento da Educação (FNDE), de recursos financeiros, em caráter suplementar, a escolas públicas, e privadas de educação especial, que possuam alunos matriculados na educação básica, e a polos presenciais do sistema Universidade Aberta do Brasil $(\mathrm{UAB})^{8}$ que ofertem programas de formação inicial ou continuada a profissionais da educação básica, com o propósito de contribuir para o provimento das necessidades prioritárias dos estabelecimentos educacionais beneficiários que concorram para a garantia de seu funcionamento e para a promoção de melhorias em sua infra-estrutura física e pedagógica, bem como incentivar a autogestão escolar e o exercício da cidadania com a participação da comunidade no controle social (BRASIL, 2013).

De acordo com a resolução, o recurso do PDDE é destinado à aquisição de material permanente e de consumo; para a realização de pequenos reparos, adequações e serviços necessários à manutenção, conservação e melhoria da estrutura física da unidade escolar; na avaliação de aprendizagem; na implementação do projeto pedagógico e no desenvolvimento de atividades educacionais.

De acordo com a resolução $n .^{\circ} 10$, de 18 de abril de 2013, os recursos do programa não podem ser utilizados em:

I - implementação de outras ações que estejam sendo objeto de financiamento por outros programas executados pelo FNDE, exceto aquelas executadas sob a égide das normas do PDDE;

II - gastos com pessoal;

III - pagamento, a qualquer título, a:

a) agente público da ativa por serviços prestados, inclusive consultoria, assistência técnica ou assemelhados; e

b) empresas privadas que tenham em seu quadro societário servidor público da ativa, ou empregado de empresa pública ou de sociedade de economia mista, por serviços prestados, inclusive consultoria, assistência técnica ou assemelhados;

IV - cobertura de despesas com tarifas bancárias; e

$\mathrm{V}$ - dispêndios com tributos federais, distritais, estaduais e municipais quando não incidentes sobre os bens adquiridos ou produzidos ou sobre os serviços contratados para a consecução dos objetivos do programa. (BRASIL, 2013, s/p).

Os recursos são repassados por intermédio de suas Entidades Executoras (EEx), Unidades Executoras Próprias (UEx) e Entidades Mantenedoras (EM), assim definidas: 
I - Entidade Executora (EEx) - prefeituras municipais e secretarias distritais e estaduais responsáveis pela formalização dos procedimentos necessários ao recebimento, execução e prestação de contas dos recursos do programa, destinados às escolas de suas redes de ensino que não possuem UEx, bem como pelo recebimento, análise e emissão de parecer das prestações de contas das UEx, representativas de suas escolas ou dos polos presenciais da UAB a ela vinculados;

II - Unidade Executora Própria (UEx) - entidade privada sem fins lucrativos, representativa das escolas públicas e dos polos presenciais da $\mathrm{UAB}$, integrada por membros da comunidade escolar, comumente denominada de caixa escolar, conselho escolar, colegiado escolar, associação de pais e mestres, círculo de pais e mestres, dentre outras entidades, responsáveis pela formalização dos procedimentos necessários ao recebimento dos repasses do programa, destinados às referidas escolas e polos, bem como pela execução e prestação de contas desses recursos; e ( $3^{\circ}$ capítulo).

III - Entidade Mantenedora (EM) - entidade privada sem fins lucrativos, qualificada como beneficente de assistência social, ou de atendimento direto e gratuito ao público, representativa das escolas privadas de educação especial, responsáveis pela formalização dos procedimentos necessários ao recebimento dos repasses do programa, destinados às referidas escolas, bem como pela execução e prestação de contas desses recursos (BRASIL, 2013, s/p).

Escolas com mais de 50 (cinquenta) alunos devem, obrigatoriamente, constituir suas UExs (Unidade Executoras). Já para as escolas com menos de 50 (cinquenta) alunos é facultada a sua constituição. Para receber o recurso do PDDE, a escola deve criar uma Unidade Executora (UEx), cuja necessidade da criação para o recebimento dos recursos deu-se a partir de 1997:

O agora Programa Dinheiro Direto na Escola (PDDE) passou também a incorporar escolas de ensino fundamental que atendessem alunos com necessidades educacionais especiais e comunidades indígenas. Em 2003, foi novamente atualizado pela Resolução n. 3 de 27/02/03, do FNDE, com base na Medida Provisória n. 2.178-36, de 24/08/2001. Desde 1997, o Programa exige, como condição para o recebimento dos recursos diretamente pelas escolas, a existência de Unidades Executoras (UEx): entidades de direito privado, sem fins lucrativos e que possuam representantes da comunidade escolar. [...] Declaradamente, o Programa opta pela criação de UEx de natureza privada como mecanismo para assegurar maior flexibilidade na gestão dos recursos repassados e ampliar a participação da comunidade escolar nessa mesma gestão (ADRIÃO; PERONI, 2007b, pp. 257-258).

Todos os anos, o Fundo Nacional de Desenvolvimento da Educação (FNDE) repassa para as escolas recursos financeiros sem a necessidade de convênio, mediante crédito do dinheiro direto em conta bancária da Unidade Executora (UEx). Como vimos, as UEx, entidades de direito privado, sem fins lucrativos, que representam a unidade escolar, são responsáveis pelo recebimento e execução dos recursos financeiros recebidos pelo FNDE. 
A função das UEx é administrar bem como receber, executar e prestar conta dos recursos transferidos por órgãos federais, estaduais, municipais, privados, doados, ou os recursos provenientes de campanhas escolares, advindos da comunidade ou de entidades beneficentes, bem como fomentar as atividades pedagógicas da escola (BRASIL, 1997).

As UEXs são encontradas em todo o território nacional, podendo ter denominações diferentes, como: Caixa escolar, nos Estados de Goiás, Maranhão, Minhas Gerais e Mato Grosso; Cooperativa Escolar, no Estado da Paraíba; Associação de Pais e Professores em Santa Catarina; Associação de Pais e Mestres, nos Estados de Mato Grosso do Sul, Pará, São Paulo e no Distrito Federal; Círculo de Pais e Mestres no Rio Grande do Sul. (BRASIL, 1997). No caso das escolas estaduais paranaenses, apesar da diversidade de denominações, predominam as registradas como Associação de Pais, Mestres e Funcionários (APMF) e, nas unidades escolares municipais de Londrina, é $\mathrm{APM}^{9}$ (Associação de Pais e Mestre), para as escolas públicas dos anos inicias do Ensino Fundamental, e APF (Associação de Pais e Funcionários) para os Centros Municipais de Educação Infantil.

Quanto ao valor repassado, a resolução $\mathrm{n}^{\circ}$ 10, de 18 de abril de 2013 informa que,

O montante devido, anualmente, às escolas públicas com UEx, aos polos da UAB e às escolas privadas de educação especial, será calculado pela soma do valor fixo, definido por estabelecimento de ensino, com o valor variável, de acordo com o número de alunos matriculados no estabelecimento, tendo como parâmetros os "Valores Referenciais de Cálculo para Repasses do PDDE" que compõem o anexo desta resolução (BRASIL, 2013, grifo do autor).

Para recebimento dos recursos, as EEx (Entidades Executoras) e as UEx (Unidades Executoras) devem realizar a adesão ao PDDE, por meio do sistema PDDEWeb ${ }^{10}$, e escolher os percentuais nos quais querem investir, despesas de custeio ou capital.

Sobre as categorias de despesas,

Os recursos recebidos e destinados para a categoria custeio são aqueles destinados à aquisição de bens e materiais de consumo e à contratação de serviços para a realização de atividades de manutenção, necessários ao funcionamento da escola. Os recursos da categoria capital são aqueles destinados a cobrir despesas com a aquisição de equipamentos e material permanente para as escolas e podem resultar em reposição ou em elevação patrimonial (BRASIL, 2003, p.14)

Conforme estabelecido, o FNDE apresenta uma tabela na qual o valor repassado é calculado a partir desses indicadores: 
Tabela 1. Valores referências de cálculo para repasses do PDDE

VALORES REFERENCIAIS DE CÁLCULO PARA REPASSES DO PDDE

1. Valor Fixo/ano $(\mathrm{VF} / \mathrm{a})=\mathrm{R} \$ 1.000,00$

a. Escola pública urbana com UEx: 1 x VF/a

b. Escola pública rural com UEx: 2 x VF/a

c. Escola privada de educação especial: 1 x VF/a

d. Polo presencial da UAB: 3 x VF/a

2. Valor Per Capita/ano (VPC/a) $=\mathrm{R} \$ 20,00$

a. Alunos de escolas urbanas ou rurais com Uex: 1 x VPC/a

b. Alunos de escolas urbanas sem Uex: 2 x VPC/a

c. Alunos de escolas rurais sem Uex: 3 x VPC/a

d. Alunos público alvo da educação especial em escola pública: 4 x VPC/a

e. Alunos de escola privada de educação especial: 3 x VPC/a

f. Alunos de polos presenciais da UAB: 1 x VPC/a

Fonte: BRASIL (2013, p. 10).

Até o presente, caracterizamos o PDDE quanto a sua criação, natureza e finalidade. No próximo item, propusemos uma reflexão que relaciona o PDDE ao processo de Reforma do Estado brasileiro, na década de 1990.

\section{O PDDE e sua relaçaõ com o Plano de Reforma do Estado}

Ao avaliar um programa educacional, é necessário verificar o contexto no qual ele foi formulado, pois se sabe que ele é constituído de lutas, pressões, conflitos e contradições, reflexos de uma condição histórica. Por isso, a importância de analisar com riqueza de detalhes as condições e os propósitos, diante dos quais os programas educacionais são concebidos e implementados. Em diversos casos, é possível inferir que o Brasil acatou as orientações da Comissão Econômica para a América Latina e Caribe (CEPAL) do Banco Mundial (BM), do Consenso de Washington que previam a diversificação das fontes de financiamento da educação pública e o incentivo ao financiamento, em regime de parceria.

É importante destacar que a concepção de gestão da educação, na perspectiva da Reforma do Estado, parte de um diagnóstico que admite a responsabilização das escolas pelo fracasso do sistema educacional ${ }^{11}$ público, definindo-o como um problema meramente gerencial, decorrente da ineficácia e incapacidade estrutural da administração pública, de garantir uma gestão de qualidade.

A redefinição do papel do Estado na educação é apresentada por meio do PDDE, que repassa do recurso federal (salário-educação) para as escolas, que, obrigatoriamente, devem ter um CNPJ. Assim, a escola continua sendo estatal, mas passa a ter a lógica privada, uma vez que insere na escola pública uma empresa de cunho privado, na perspectiva de quase mercado. A constituição do PDDE, por meio da instituição obrigatória da UEx (Unidade Executora), pode ser considerada uma estratégia de descentralização das ações do governo federal nos municípios e estados e, consequentemente, para a sociedade, repassando para esta a responsabilidade de aplicação, prestação de contas dos recursos financeiros e manutenção física das escolas, sendo esta 
uma característica da redefinição do papel do Estado, contemplada no Plano Diretor da Reforma do Aparelho do Estado (1995). Além disso, abre a possibilidade de angariar recursos de fontes privadas, em regime de parcerias e/ou por meio de ações coletivas, festas, bingos e outros, eximindo cada vez mais o Estado das suas obrigações, enquanto mantenedor do serviço público.

Neste sentido, passa a caber ao Estado apenas o controle e a regulamentação das ações que serão desenvolvidas e à escola, além das obrigações pedagógicas, administrativas e outras, a captação de recursos para o desenvolvimento de suas atividades. Isso ocorre, porque os parcos recursos que chegam na escola via PDDE, não cobre totalmente as necessidades financeiras das escolas, cuja gestão se vê quase que na obrigatoriedade de angariar recursos privados, para sanar os problemas mais imediatos que vão emergindo em seu cotidiano.

Em tese, o Programa lida com a necessidade da participação popular na gestão da escola. A APMF, que é a UEx (Unidade Executora), é uma entidade jurídica de direito privado, criada com a finalidade de colaborar para o aperfeiçoamento do processo educacional, para a assistência ao escolar e para a integração escola-comunidade.

Assim, o PDDE trouxe um importante debate em torno da utilização dos recursos financeiros no espaço escolar, por um lado, introduzindo práticas mais participativas, e, por outras representações de caráter privado na escola. Podemos inferir que a institucionalização das UExs compõe um processo de instauração de um novo padrão de gestão nas escolas e responsabiliza uma entidade privada (UEx) por decisões políticas significativas.

Inicialmente, o PDDE seria uma das ferramentas do processo de democratização da escola. Contudo, pesquisas

[...] demonstram que as bases político-pedagógicas do PDDE, a despeito de possibilitar às unidades escolares a gestão de pequenos recursos, por meio de entidade privada, não contribuíram efetivamente para a democratização dos processos de deliberação coletiva e, ainda, restringiram a autonomia à gestão financeira da escola (DOURADO, 2007, p. 934).

Importante chamar atenção para o discurso da autonomia financeira e da descentralização, uma vez que que serve para reforçar a manutenção do caráter privatista da educação. Assim, há a necessidade de discernir descentralização de poder com desconcentração de tarefas relativas à gestão financeira. Dourado (2007) ainda destaca que se trata de um cenário ambíguo que, ao mesmo tempo em que proporciona políticas de caráter democrático na gestão da escola, reforça a ênfase gerencial, tecnicista e produtivista.

Enfim, diversas análises demonstram que, no Brasil, houve uma desconcentração de ações e transferência de competências de cunho técnico e financeiro de um ente federado para outro. O PDDE, em tese, propicia a democratização da escola pública, que, por meio dos repasses financeiros, supre as escolas com investimentos na infraestrutura física e pedagógica, propiciando a participação social e autonomia financeira para a melhoria da qualidade do ensino.

A participação da comunidade na manutenção da escola pública foi prevista pelo processo de Reforma do Estado no Brasil, por meio do qual a sociedade passa a ser responsável por parte dos compromissos financeiros dos serviços sociais. O PDDE e a Reforma do Estado apresentam uma grande relação, visto que este focaliza ações no campo educacional (descentralização) e caracteriza-se como um programa de caráter suplementar, 
uma vez que o Estado não pretende assumir a totalidade das despesas de manutenção e desenvolvimento da escola pública.

O PDDE agilizou, no primeiro momento, a assistência financeira às escolas públicas. No entanto, a autonomia concedida aos sistemas de ensino, pautada em um modelo neoliberal de terceira via, procurou desconcentrar tarefas, estabelecer parcerias e não visou a democratizar verdadeiramente a gestão do espaço escolar.

\section{Considerações finais}

Neste texto, em um esforço de atender ao princípio da totalidade, apresentamos o contexto macro no qual o PDDE foi desenvolvido. Para tanto, discutimos os elementos que compunham a política educacional brasileira, na década de 1990 e os antecedentes históricos e econômicos que foram suas bases. Vimos que, diante da crise econômica mundial eclodida nos anos de 1970 e 1980, foram desencadeadas políticas em âmbitos internacionais, que passaram a influenciar, dentre outras, as reformas educacionais. Este conjunto de determinações produzidas com o objetivo de conter a crise influenciou a Reforma do Aparelho do Estado, na década 1990.

A análise do Plano Diretor da Reforma do Aparelho do Estado (PDRAE), elaborado pelo Ministério da Reforma e Administração do Estado (MARE), foi de fundamental importância para percebermos a reconstrução da administração pública. Consideramos que tal reconstrução atendeu às determinações do mercado, com a justificativa de que a natureza burocrática e regulatória do Estado foram elementos causadores da crise econômica do país. O governo federal, a fim de alcançar a qualidade e eficiência em sua administração, dentre outras medidas, procurou descentralizar as responsabilidades de gestão e financiamento público para Estados subnacionais e municípios.

Neste sentido, vimos que o PDDE foi criado em um período de influência da política neoliberal e contribuiu para reforçar as iniciativas da terceira via, na área da educação. Em resposta a questão norteadora do texto, sobre a possibilidade e limite da democratização da gestão escolar, por meio do PDDE, concluímos que há, aparentemente, uma falsa democracia, uma vez que a participação da comunidade escolar é incitada, no sentido de induzir a arrecadação de recursos financeiros privados para a escola pública, quando os recursos públicos do PDDE, não são suficientes. Assim, estimula-se cada vez mais as parcerias público-privadas. Isso fere o princípio da gratuidade do ensino público, expresso nas políticas para a educaçãoe contribui para gerar, dentre várias mudanças, as propostas de modernização da gestão e de estratégias gerenciais nas escolas públicas, que têm como uma das estratégias a responsabilização dos indivíduos e das instituições escolares pelo sucesso e/ou fracasso, na perspectiva da meritocracia. Assim, as escolas que se destacam são aquelas que desenvolvem uma gestão criativa, no sentido de ampliar as possibilidades de buscar recursos financeiros em fontes diversificadas, para além do setor público. É a proposta da terceira via em pleno desenvolvimento. 


\section{Referências}

ADRIÃO, Theresa; PERONI, Vera Maria Vidal. Implicações do Programa Dinheiro Direto na Escola para a gestão da escola pública. Educação e Sociedade, Campinas, v. 28, n. 98, p. 253-267, jan./abr., 2007b.

ADRIÃO, Theresa; PERONI, Vera Maria Vidal. Programa Dinheiro Direto na Escola: uma proposta de redefinição do papel do Estado na Educação.Brasília: Instituto Nacional de Estudos e Pesquisas Educacionais Anísio Teixeira, 2007. Disponível em:

<http://www.publicacoes.inep.gov.br/portal/download/473>. Acesso em: 05 fev. 2014.

ADRIÃO, Theresa; PERONI, Vera Maria Vidal. Público não-estatal: estratégias para o setor educacional brasileiro. São Paulo: Xamã, 2005.

ANDERSON, Perry. Balanço do neoliberalismo. In: SADER, Emir, GENTILI, Pablo. (Org.). Pós-neoliberalismo: as políticas sociais e o Estado democrático. Rio de Janeiro: Paz e Terra, 1995.

ARRETCHE, Marta Teresa da Silva. Uma contribuição para fazermos avaliações menos ingênuas. In: BARREIRA, Maria Cecília Roxo Nobre; CARVALHO, Maria do Carmo Brant (orgs). Tendências e Perspectivas na Avaliação de Políticas e Programas Sociais. São Paulo: IEE/PUC, 2001.

BRANCO, Mylene Mariani Pereira. Programa Dinheiro Direto na Escola: o papel das unidades executoras na gestão de escolas públicas do município de Araçatuba - de 2003 a 2005. 2006. 119 f. Dissertação (Mestrado em Educação) - Universidade Católica Dom Bosco, Campo Grande. 2006.

BRASIL. Ministério da Administração e Reforma do Estado. Plano Diretor da Reforma do Aparelho do Estado. Brasília: MARE, 1995. Disponível em:

<http://www.bresserpereira.org.br/documents/mare/planodiretor/planodiretor.pdf >. Acesso em: 10 nov. 2014.

BRASIL. Ministério da Educação. Fundo Nacional de Desenvolvimento da Educação. Resolução $n^{o}$ 3, de 4 de março de 1997. Brasília: FNDE, 1997. Disponível em: <https://www.fnde.gov.br/fndelegis/action/UrlPublicasAction.php>. Acesso em: 15 jan. 2015.

BRASIL. Ministério da Educação. Fundo Nacional de Desenvolvimento da Educação. Resolução $n^{\circ} 10$, de 18 de abril de 2013. Brasília: FNDE, 2013. Disponível em:

$<$ https://www.fnde.gov.br/fndelegis/action/UrlPublicasAction.php?acao=abrirAtoPublico\& sgl_tipo $=$ RES\&num_ato $=00000010 \&$ seq_ato $=000 \& v l r \_a n o=2013 \& s g l \_$orgao $=C D / F N D E /$ MEC>. Acesso em: 10 out. 2014.

BRASIL. Ministério da Educação. Manual de Orientações Básicas do PDDE/2003. Brasília: FNDE, 2003. 
CARDOSO. Fernando Henrique. Notas sobre a reforma do estado. Novos Estudos. CEBRAP. p. 5-12, 1998. Disponível em:<http://www.e-

law.net.br/ensaios/Notas_sobre_a_reforma_do_Estado.pdf >. Acesso em: 26 de nov. 2014.

DOURADO, Luiz Fernandes. Políticas e gestão da educação básica no Brasil: limites e perspectivas. Educação e Sociedade, v. 28, n. 100, p. 921-946, 2007. Disponível em:〈http://www.scielo.br/pdf/es/v28n100/a1428100.pdf>. Acesso em: 03 mai. 2014.

EVANGELISTA, Olinda. Apontamentos para o trabalho com documentos de política educacional. I Colóquio A Pesquisa em trabalho, educação e Políticas Educacionais. Belém: UFPA, 2009. Disponível em: <http://pt.scribd.com/doc/211971320/texto-OlindaPDF>. Acesso em: 10 set. 2014.

FIORI, José Luis. 60 lições dos 90: uma década de neoliberalismo. Rio de Janeiro: Record, 2001.

FRIGOTTO, Gaudêncio; CIAVATTA, Maria. Educação básica no Brasil na década de 1990: subordinação ativa e consentida à lógica do mercado. Educação e Sociedade, São Paulo, v. 24, n. 82, p. 93-130, abr. 2003. Disponível em:

<http://www.scielo.br/pdf/es/v24n82/a05v24n82.pdf>. Acesso em: 17 jun 2014.

OLIVEIRA, Maria Marly. Como fazer pesquisa qualitativa. Petrópolis: Vozes, 2007.

PEREIRA, Luis Carlos Bresser. Reforma do Estado para a cidadania. São Paulo, SP: Editora 34, 1998.

PERONI, Vera Maria Vidal. As redefinições da relação público/privado e implicações para a democratização da educação. Inter-ação (UFG), v. 35, p. 1-17, 2010.

PERONI, Vera Maria Vidal. As Relações entre o Público e o Privado nas Políticas Educacionais no Contexto da Terceira Via. Currículo sem Fronteiras, v. 13, p. 234-255, 2013.

SANTANA, Kátia de Cassia. Efeitos do programa Dinheiro Direto na Escola na gestão escolar. 2011. 174 f. Dissertação (Mestrado em Educação). Universidade Federal de Viçosa, Viçosa, 2011.

SHIROMA, Eneida Oto; MORAES, Maria Célia M. de; EVANGELISTA, Olinda. Política Educacional. Rio de Janeiro: DP\&A, 2000.

VIEIRA, Evaldo. A social-democracia, longo caminho até a terceira via. Currículo sem Fronteiras, São Paulo, v. 13, n. 2, p. 182-203, maio/ago. 2013.

WOOD, Ellen Meiksins. Democracia contra o capitalismo: a renovação do materialismo histórico. São Paulo: Boitempo, 2006. 


\section{Notas}

${ }^{1}$ Mestre em Educação. Docente da Universidade do Norte do Paraná UNOPAR e da Rede Municipal de Ensino - Londrina-Pr.

${ }^{2}$ Pós doutora em Educação pela UFRGS. Docente e pesquisadora da Universidade Estadual de Londrina, Paraná, Brasil.

${ }^{3}$ O keynesianismo defendido pelo economista inglês John Maynard Keynes (1883-1946), trata-se de um conjunto de medidas políticas adotadas aos países no período pós-guerra, com o intuito de o Estado proporcionar amplos serviços sociais em dois principais princípios: a busca do pleno emprego e o desenvolvimento, acelerado por investimentos estatais.

${ }^{4}$ É uma organização das Nações Unidas (ONU), criada em 1948 e composta por 41 países membros e 7 associados da América Latina e o Caribe, com o objetivo de coordenar as políticas de desenvolvimento econômico e social dos países da América Latina e do Caribe.

${ }^{5} \mathrm{O}$ termo ortodoxo diz respeito àquele que segue fielmente um princípio, uma norma ou uma doutrina. $\mathrm{O}$ neoliberalismo ortodoxo é reação de cunho teórico e político que iria contra ao Estado intervencionista de bem-estar social. Indica a não-intervenção do Estado em prol da liberdade individual e da competição entre os agentes econômicos, sendo este o pressuposto da prosperidade econômica (ANDERSON, 1995).

${ }^{6}$ O Ministério da Administração Federal e Reforma do Estado (MARE) foi criado no início do Governo de Fernando Henrique Cardoso, em 1995.

${ }^{7}$ A propriedade pública não-estatal é chamada por muitos autores de Terceiro Setor, nem Estado, nem mercado. O Terceiro Setor é caracterizado como o Público não Estatal e pressupõe a existência do primeiro e segundo, Estado e Mercado (PERONI, 2010, p. 5).

${ }^{8}$ A partir da Lei 12.695, de 25 de julho de 2012, o Programa passou a atender, também, a polos presenciais do sistema Universidade Aberta do Brasil que ofertam programas de formação inicial e continuada a profissionais da educação básica. Neste estudo, faremos o recorte, abordando as escolas de educação básica.

${ }^{9} \mathrm{~A}$ APM e a APF são entidades jurídicas de direito privado, criadas com a finalidade de colaborar para o aperfeiçoamento do processo educacional, para a assistência ao escolar e para a integração escolacomunidade.

${ }^{10}$ É um aplicativo que possui interatividade com a Internet para obter os dados cadastrais de cada escola e enviá-los ao FNDE. Encontra-se disponível em: https://www.fnde.gov.br/pdde/.

${ }^{11}$ Importante destacar que muitos autores, entre eles Saviani, comentam a inexistência de um "Sistema Nacional de Educação" no Brasil. Para mais informações recomenda-se a leitura do texto disponível em $\langle$ http://www.scielo.br/pdf/es/v31n112/07.pdf〉.

Recebido: Março/2016.

Aprovado: Abril/2017. 